УДК $327 ; 339.942$

\title{
A.A. Попов
}

\section{ЭКОНОМИЧЕСКИЕ МОТИВЫ СОТРУДНИЧЕСТВА СТРАН СЭВ В СФЕРЕ ДОБЫЧИ ИСКОПАЕМЫХ РЕСУРСОВ (1950-е - 1980-е гг.) ${ }^{1}$}

\begin{abstract}
В статье на основе архивных материалов РГАЭ проанализированы экономические стимулы кооперации стран Совета Экономической Взаимопомощи в добыче ископаемых ресурсов. Реконструирован ход дискуссии о возможности стандартизации взаимных инвестиций социалистических стран. Механизмы инвестирования рассмотрены в логике функционирования плановых систем на основе модели Я. Корнаи. Выявлено, что одним из ключевых условий успешной реализации проектов была возможность увеличения притока твердой валюты для всех сотрудничавших сторон. Индивидуальный характер большинства реализованных проектов предопределил провал попыток стандартизации этой формы сотрудничества в рамках нормативной базы СЭВ. В условиях преобладания двухсторонних отношений над многосторонними формами кооперации социалистических стран, попытки институционализации отдельных форм в рамках СЭВ лишь фиксировали сложившуюся ситуацию.
\end{abstract}

Ключевые слова: СЭВ, социалистический лагерь, Холодная война, европейская интеграция.

DOI: $10.35634 / 2587-9030-2020-4-2-196-204$

\section{Введение}

История Совета Экономической Взаимопомощи долгое время оставалась на периферии внимания историков Холодной войны, но в последние полтора десятилетия ситуация изменилась. Историки стали больше внимания уделять истории кооперации социалистических стран, поскольку стало ясно, что процесс кооперации восточноевропейских стран с одной стороны, позволяет значительно расширить представления об общеевропейских интеграционных процессах второй половины XX века [5; 15], а с другой - точнее реконструировать механизмы функционирования плановых экономик.

Длительное время господствовал упрощенный подход к анализу плановых экономик. В противоположность рыночным системам характерной чертой социалистических стран считалось стремление к автаркии. Но развитие европейских социалистических стран после смерти Сталина невозможно объяснить в терминах автаркии. Сейчас даже для периода правления Сталина экономический «изоляционизм» СССР ставится под сомнение [20, Р. 56].

Совет Экономической Взаимопомощи (СЭВ), созданный в 1949 г., в первые пять лет своего существования действительно был скорее красивой вывеской для сети двухсторонних отношений СССР и восточноевропейских стран. При этом Советский Союз использовал механизм советников СЭВ в качестве еще одного механизма контроля [18, Р. 31]. Однако, со сменой власти в СССР, и на фоне экономического и политического кризисов середины 1950х гг., когда Кремль был вынужден ослабить контроль за внутренней политикой социалистических стран, и СЭВ стал реальной площадкой для многосторонних переговоров.

Показательно, что инициатива исходила не только и не столько из Москвы. Свои проекты сотрудничества присылали из Праги, Берлина, Варшавы и Бухареста. Эта активизация международного сотрудничества началась тогда, когда отношения между многими странами соц.лагеря были весьма напряженными из-за взаимных задолженностей, несоблюдения торговых договоров, политических претензий, а сама природа плановых экономик не располагала к такого рода кооперации. Собственно, в общем виде это противоречие сводится к проблеме мотивов экономического сотрудничества плановых экономик.

В данной статье этот вопрос рассматривается на примере кооперации в сфере добычи ископаемых ресурсов. Поскольку дефицит сырья остро стоял на протяжении всего существования СЭВ, тесно переплетаясь с проблемой ограниченности инвестиций, коллективные попытки его преодоления, их успехи и провалы, могут служить хорошим материалом для понимания механизмов функционирования и внутренней логики социалистической кооперации. Исследование основано на материалах Российского государственного архива экономики и Российского государственного архива новейшей истории.

\footnotetext{
${ }^{1}$ Исследование выполнено за счет гранта Российского научного фонда (проект № 19-78-10023).
} 


\section{Методология}

Разумеется, функционеры национальных плановых органов и СЭВ регулярно заявляли о необходимости расширения взаимных инвестиций и международного сотрудничества. Однако реальных примеров такого рода кооперации было не очень много. В крупных международных проектах, страны как правило собственными силами строили участки нефтепроводов, электросетей или железных дорог на своей территории.

Даже с точки зрения теории плановой экономики такие вложения были маловероятны. Согласно теории Яноша Корнаи стремление к ускорению экономического роста в ресурсно-ограниченных системах вело к запуску максимального числа национальных инвестиционных программ. Это приводило к возникновению инвестиционной напряженности. Каждый руководитель проекта стремился получить дополнительные капиталовложения, претендуя на дополнительные нераспределенные ресурсы или ресурсы других проектов. Модель Корнаи предполагала появление «инвестиционного голода» в системе, который возрастал и ослабевал в рамках «инвестиционного цикла» [15, Р. 801-819; 3, С. 210-215]. Примечательно, что в вообще Корнаи не описывал иностранных инвестиций, хотя подчеркивал влияние именно внешнеэкономических факторов на стадии инвестиционного цикла внутри страны.

Кажется очевидным, что «инвестиционный голод» ограничивал и взаимные инвестиции. Если в каждой социалистической стране наблюдалась инвестиционная напряженность, капиталовложения в производство необходимых ресурсов на территории другой стороны были дестабилизирующим фактором для экономики. Иностранные инвестиции сокращали объем внутренних инвестиций и усугубляли инвестиционный голод. Строительство предприятий или инфраструктурных объектов на своей территории на средства других стран вело к тому же результату. Возникали внеплановые траты на строительство транспортной и социальной инфраструктуры. В логике функционирования плановых экономик, когда все ресурсы уже были распланированы иностранные инвестиции прямо угрожали реализации национальных хозяйственных планов и страны-инвестора, и страны-реципиента.

В рамках модели Корнаи, иностранные инвестиции были возможны только, когда они позволяли снизить инвестиционную напряженность внутри страны. Это утверждение, абсурдное для рыночных систем, вполне логично для плановых экономик, учитывая проблемы их внешней торговли: неконвертируемость валют, ограниченность рынков сбыта, дефицит определенных видов ресурса. Для выполнения условий появления взаимных иностранных инвестиций было достаточно, чтобы в перспективе они снижали издержки (или увеличивали доход) в твердой валюте. Твердая валюта была единственным ресурсом, который плановые экономики не могли производить самостоятельно, а получение его обходилось им чрезвычайно дорого ${ }^{2}$. Сокращение валютных издержек или увеличение валютной выручки значительно сокращали дефицит капиталов.

Тем не менее, как эти теоретические конструкции соотносились с реальной практикой, где взаимодействовало сразу несколько относительно независимых субъектов?

\section{Результаты}

После политических кризисов в Польше и Венгрии в 1956 г., давление Советского Союза на восточноевропейские страны существенно ослабло. При этом необходимость решения экономических проблем не исчезла - дефицит ресурсов только усиливался. Восточноевропейские страны начали более активно и независимо развивать экономические отношения как с социалистическими, так и с капиталистическими странами.

Двусторонние отношения на периферии социалистического лагеря, хотя почти не привлекали внимания СССР, требовали легитимации другими членами блока. В этих условиях Совет экономической взаимопомощи под руководством нового председателя Фаддеева стал главной площадкой для многостороннего диалога по вопросам экономического и научно-технического сотрудничества [19. S. 93-94].

Роль структур СЭВ в процессе расширения кооперации, вероятно, оставалась скромной. Абсолютное большинство совместных проектов по добыче ископаемых ресурсов на территории других стран были запущены по итогам двусторонних переговоров. Но в Секретариате СЭВ сформировался подход к этим проектам как к особой форме многостороннего взаимодействия.

\footnotetext{
2 Любопытно, что в исследованиях экономистов социалистических стран гораздо больше внимания уделялось влиянию взаимных капитальных вложений на внешнеторговые процессы: Караваев В.П. Интеграция и инвестиции: проблемы сотрудничества стран СЭВ. М: Наука, 1978.
} 
Впервые круг этих проектов был очерчен в 1963 - 1966 гг. в ходе дискуссий вокруг разработки «Основных принципов сотрудничества между заинтересованными странами-членами СЭВ в развитии добычи и переработки сырья в странах, располагающих благоприятными условиями, с целью правильного распределения между странами нагрузки, связанной с развитием сырьевой базы» [далее «Основные принципы»]. Затем, все подобные проекты были перечислены в «Информации о развитии и формах сотрудничества в строительстве промышленных объектов совместными усилиями заинтересованных стран-членов СЭВ» [далее - «Информация»], представленной в августе 1967 г. [8, Д. 45. Л. 55об].

В 1950е гг. основным кредитором Восточной Европы был Советский Союз (см. табл. 1). Кроме него займы в гораздо меньших объемах предоставляли технологические лидеры блока - ГДР и Чехословакия. Необходимо оговорить, что я располагаю только данными из документов СЭВ, которые являются неполными, поскольку не все страны-члены организации их предоставили. Но даже эти данные представляют ценность, поскольку информация по взаимному кредитованию социалистических экономик в принципе публиковалась крайне редко.

Предоставление кредитов странами СЭВ в 1950-1957 гг. [7, Д. 21. Л. 20]

Таблица 1

\begin{tabular}{|c|c|c|c|c|c|c|c|c|c|}
\hline \multirow{3}{*}{$\begin{array}{l}\text { Страны-члены } \\
\text { СЭВ, } \\
\text { предоставившие } \\
\text { кредиты }\end{array}$} & \multicolumn{9}{|c|}{ Предоставленные кредиты (млн руб) } \\
\hline & \multirow[b]{2}{*}{ Всего } & \multicolumn{8}{|c|}{ Включая } \\
\hline & & 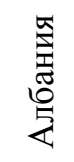 & 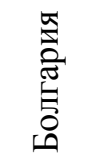 & 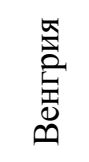 & 会 & $\begin{array}{l}\text { 畄 } \\
\text { 宫 }\end{array}$ & 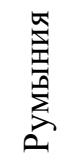 & 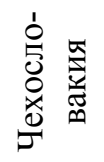 & $\begin{array}{c}\text { Другие } \\
\text { народные } \\
\text { демократии }\end{array}$ \\
\hline Всего & 18599 & 774 & 1369 & 1527 & 1793 & 4852 & 800 & 122 & 7789 \\
\hline \multicolumn{10}{|c|}{ Включая } \\
\hline $\mathrm{CCCP}$ & 16918 & 613 & 1335 & 1121 & 1793 & 3992 & 690 & 122 & 7120 \\
\hline ГДР & 1133 & 101 & * & 60 & - & 400 & 110 & - & * \\
\hline Чехословакия & * & * & * & 230 & 410 & 460 & - & - & * \\
\hline
\end{tabular}

Для проектов долевого участия в сырьевой сфере главными кредиторами были Чехословакия и ГДР (см. табл. 2). Благодаря развитой промышленности они обладали технологиями, товарами и капиталами, которые могли быть интересны социалистическим странам. Обе страны остро нуждались в дефицитных ресурсах для своей промышленности (железной руде, рудах цветных металлов, угле, коксе). Наибольшими запасами этих ресурсов располагали Советский Союз и Польша.

Таблица 2

Предоставление кредитов странами СЭВ в 1957-1963 гг.

\begin{tabular}{|c|c|c|c|c|c|c|c|c|c|}
\hline \multirow[b]{3}{*}{$\begin{array}{c}\text { Страны-члены СЭВ, } \\
\text { предоставившие } \\
\text { займы }\end{array}$} & \multicolumn{9}{|c|}{ Предоставленные займы (млн руб) } \\
\hline & \multirow[b]{2}{*}{ Всего } & \multicolumn{8}{|c|}{ Включая } \\
\hline & & 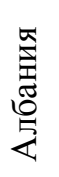 & 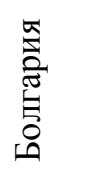 & 营 & 会 & 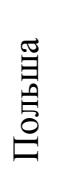 & 离 & 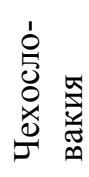 & СССР \\
\hline ГДР & 106 & - & 9,1 & - & - & 90 & - & - & 6,9 \\
\hline Чехословакия & 244,1 & - & 11 & - & - & 191 & - & $\begin{array}{llll}- & \\
\end{array}$ & 42,1 \\
\hline Болгария & 10,1 & - & $\begin{array}{llll}- & & & \\
\end{array}$ & - & - & - & - & - & 10,1 \\
\hline Венгрия & 6,9 & - & $\begin{array}{llll}- & & & \\
\end{array}$ & - & - & - & - & - & 6,9 \\
\hline Польша & 81 & - & $\begin{array}{llll}- & & & \\
\end{array}$ & - & - & $\begin{array}{lll}- & & \\
-\end{array}$ & - & - & 81 \\
\hline Всего & 448,1 & - & 20,1 & - & - & 351 & - & - & 147 \\
\hline
\end{tabular}


Польша была главным реципиентом Чехословацких и восточногерманских кредитов. Она была ближе географически, больше пострадала от экономического кризиса середины 1950x гг. и имела меньше возможностей для внутреннего инвестирования $[21]^{3}$. Для Советского Союза технологии и оборудование ГДР и Чехословакии представляли меньший интерес, при том, что возможности распределения собственных инвестиций в разработку месторождений и внутренний спрос на ресурсы были гораздо выше, чем в Польше.

Советский Союз в кредитовании проектов долевого участия в сырьевом секторе в 1957-1963 гг. почти не участвовал. На советской территории реализовывались только два приграничных проекта, почти полностью ориентированные на рынки восточноевропейских стран СЭВ. Но при этом советское руководство в конце 1950х гг. рассматривало возможности создания совместных предприятий с капиталистическими странами. Помимо описанных примеров, советско-японского сотрудничества [20, Р.106], велись переговоры со странами Северной Европы. К примеру, в 1957-1958 гг. шли переговоры с Норвегией о совместном строительстве Борисоглебской электростанции. Позднее Совет Министров СССР отменил проект, ссылаясь на нехватку валюты [11, Д. 225. Л.72].

При этом попытка институализации в рамках СЭВ подобного рода инвестирования была предпринята только летом 1963 г. Разработка «Основных принципов сотрудничества между заинтересованными странами-членами СЭВ в развитии добычи и переработки сырья в странах, располагающих благоприятными условиями, с целью правильного распределения между странами нагрузки, связанной с развитием сырьевой базы» [9, Д. 27. Л. 89] затянулась на три года, и в 1966 г. закончилась провалом.

Национальные плановые органы не могли определить насколько эффективны капиталовложения в другие страны. Решением этой проблемы в СЭВ занимался Отдел методологии и экономических исследований Секретариата СЭВ. В рамках Постоянной Комиссии по экономическим вопросам была создана специальная рабочая группа по эффективности капитальных вложений. В ноябре 1963 г. она рассмотрела «Методические положения по вопросу о применении методики сравнения экономической эффективности капитальных вложений в странах СЭВ к случаям строительства объектов, представляющих интерес для нескольких стран» [10, Д. 31. Л. 12.] [далее - «Методические положения»]. Советская часть Постоянной Комиссии придерживалась позиции, что данный документ должен быть основой для разработки «Основных положений». Но «Методические положения» не удовлетворяли многие страны-члены СЭВ. В 1964 г. речь шла уже о «Временной методике сравнения экономической эффективности капитальных вложений в странах-членах СЭВ». Представители Польши отмечали, что «существенная причина трудностей в установлении общих формул заключается в том, что ...экономический характер затрат и выгод в период погашения кредита не вмещается в рамках, установленных во Временной методике понятий и способов расчета» [10, Д. 31. Л. 32.]. На итоговом совещании в 1966 г. эксперты стран раскритиковали итоговую версию «Основных принципов» и она не была принята. После чего такой вариант стандартизации уже не имел смысла.

При этом к середине 1960х в целом были решены проблемы дефицита энергоносителей и коксующегося угля, угрожавшие срывом планов индустриализации для всех восточноевропейских стран; уменьшились дисбалансы двусторонней торговли внутри блока.

Парадоксальным образом, изменение экономических условий снижало как желание странкредиторов выделять средства, так и условия, на которых страны-реципиентов были готовы их получать. В 1964 году польские власти предлагали всем заинтересованным странам поучаствовать в строительстве топливно-энергетического комбината «Белхатув», шахты по добыче цинка в Олькуше и предприятий по добыче медной руды в Легницко-Глоговском медном бассейне [23, S. 21.]. Участие в последнем проекте предполагало для стран СЭВ «покрытие всех затрат, связанных с созданием указанных мощностей, а именно затрат на геолого-поисково-разведочные работы, проектирование и строительство рудников, обогатительных фабрик и металлургических заводов, а также затрат на строительство жилых, коммунальных и социально-бытовых объектов. Это участие должно быть осуществлено в форме поставок всего необходимого оборудования, в частности бурового оборудования, оборудования для проходки стволов, компрессоров, подъемных установок и других, за исключением того оборудования, которое ПНР сама производит. Заинтересованные страны также должны нести затраты на необходимый импорт оборудования из капиталистических стран в конвертируемых валютах» [8, Д. 45. Л. 58. ]. Фактически, это означало перекладывание сопутствующих издержек и рисков на инвестора.

\footnotetext{
${ }^{3}$ Польша была сырьевой базой для соседей: ЧССР и ГДР, чем удачно воспользовалось правительство В. Гомулки, отстоявшее собственные условия экономического сотрудничества: Skrzypek A., Mechanizmy autonomii: Stosunki posko-radieckie 1956-1965. Pułtusk-Warszawa: Wyższ Szkoła Humanistyczna in. A. Gieysztora, 2005. S. 120.
} 
Показателен пример польско-чехословацких проектов по расширению добычи угля, меди и серы. После начала поставок сырья с построенных на инвестиции предприятий, Чехословакия сократила долю импорта из капиталистических стран в общей структуре своего импорта меди с 54,8 \% в 1960 г. до $12 \%$ в 1975 г., серы - 28,6 \% до $1 \%$. При этом доля Польши в чехословацком импорте возросла для меди с $1 \%$ до $21,2 \%$, а для серы с $0,04 \%$ до 64,3\%. Еще более впечатляющим выглядит изменение доли экспорта в капиталистические страны в общей структуре экспорта польской меди и серы, которые выросли в абсолютных цифрах в 770 и 25,6 раз соответственно. Чехословакия не только решила проблему дефицита важнейших видов сырья, но и сократила валютные издержки, а Польша значительно увеличила валютную выручку. Подобная ситуация наблюдалась во всех рассматриваемых проектах конца 1950x - начала 1960х гг., с той лишь разницей, что отдача в валюте не всегда носила настолько прямой и ярко выраженный характер.

Ситуации, когда иностранные инвестиции внутри СЭВ вели к увеличению объемов доступной твердой валюты и у страны-реципиента, и у страны-кредитора, были всегда уникальными. Стандартизировать условия, тем более по мере снижения остроты дефицита сырья было практически невозможно.

После провала «Основных принципов» попытки создания институциональную основу для взаимного инвестирования в СЭВ продолжились. В конце концов, с середины 1960х гг. необходимость углубления социалистической интеграции была очевидна, а «Основные принципы» были лишь одним из возможных вариантов.

В конце 1960х гг. работа по разработке основ интеграции социалистических стран концентрировалась вокруг одного документа - «Комплексной программы дальнейшего углубления и совершенствования сотрудничества и развития социалистической экономической интеграции стран-членов СЭВ» [далее - Комплексная программа]. Программа должна была охватить все возможные варианты экономического сотрудничества стран.

В июле 1969 г. отдел Сводных экономических работ представил «Анализ состояния экономики стран-членов СЭВ и экономического сотрудничества между ними и тенденции их дальнейшего развития в 1961-1970 гг.». В документе давалась характеристика как общей картины сотрудничества странчленов СЭВ, так и их взаимодействие по отдельным отраслям. Примечателен он тем, что в нем, как и в «Информации» 1967 г., перечислялись все основные совместные проекты в сфере добычи сырья.

Одним из важных отличий от содержания «Информации» стал упор на развитие сотрудничества в сфере производства топлива и металлургической продукции. Авторы прямо отмечали, что «в ряде стран-членов СЭВ потребности в топливе и электроэнергии растут быстрее, чем собственное их производство, роль экономического сотрудничества и взаимопомощи должна еще более возрасти... дальнейшее перспективное решение проблем обеспечения топливом и электроэнергией стран-членов СЭВ может быть осуществлено только в результате их совместных действий» [8, Д. 78. Л. 48. ]. Это утверждение может показаться очевидным и даже чрезмерным, поскольку страны СЭВ итак реализовывали совместные проекты в топливной и энергетической сферах. Самым ярким примером было строительство и эксплуатация нефтепровода «Дружба» и энергосистемы «Мир». Однако два этих проекта в целом не предполагали взаимных инвестиций: каждая страна строила собственный участок нефтепровода и энергосистемы собственными силами и на собственные средства ${ }^{4}$. Акцент на необходимости расширения сотрудничества в этих сферах, таким образом, выглядел оправданным. Также как указание на необходимость поиска «возможностей кооперирования капитальных вложений и форм координации планов капитальных вложений в развитие отдельных отраслей и объектов черной металлургии заинтересованных стран-членов СЭВ» [8, Д. 78. Л. 60 ], где, несмотря на определенные успехи, ощущался дефицит инвестиций.

Следует отметить также, что в немалой степени стремлению к кооперации способствовал устойчивый рост в конце 1960х гг. цен на мировых рынках на энергоносители и металлургическую продукцию.

В самой Комплексной программе, принятой в 1971 г., про взаимные инвестиции в сфере строительства совместных предприятий, говорилось лишь в общих словах как об одной из форм сотрудничества для удовлетворения потребностей в важнейших видах топлива и сырья. Комплексная программа предполагала разработку согласованных планов международных интеграционных мероприятий (СПМИМов).

\footnotetext{
${ }^{4}$ За исключением польской ветки «Дружбы», которая была построена специалистами ГДР в счет будущего транзита газа.
} 
Впрочем, первый СПМИМ появился только через четыре года и охватывал период 1976-1980 гг. $[8$, Д. 152]. На момент его публикации уже реализовывалось несколько крупных проектов, кредиты возвращались продукцией тех предприятий, на которые выделялись. В 1972 г. было подписано соглашение о строительстве Усть-Илимского целлюлозного завода в СССР [8, Д. 133. Л. .2-5], в 1973 г. сходное соглашение о расширении Кимбаевского асбестового горно-обогатительного комбината, в 1974 г. - об освоеннии Оренбургского газоконденсантного месторождения и строительство газопровода из Оренбурга до западной границы СССР в счет будущих поставок газа [8, Д. 176. Л. 63-70 ].

Все эти проекты предполагали строительство на территории СССР, далеко от его западной границы. Это принципиально отличало их от проектов предыдущего периода, рассмотренных ранее. В 1960е гг. СССР не был главным реципиентом восточноевропейских инвестиций, а построенные на его территории на средства заинтересованных стран предприятия располагались в приграничных районах.

Практическая реализация СПМИМа увязывалась с разработкой долгосрочных целевых программ сотрудничества (ДЦПС). Такие программы были приняты по пяти основным направлениям: в области энергетики, топлива и сырья; сельского хозяйства и пищевой промышленности; машиностроения; промышленных товаров народного потребления; транспортных связей [13, С. 62]. ДЦПС в области энергетики, топлива и сырья нефтегазовые проекты появилась в 1978 г. В рамках этой ДЦПС в планах до 1990 г. предполагалось строительство совместными усилиями заинтересованных стран целого ряда добывающих предприятий [8, Д. 248]. К ним были отнесены, предприятие для добычи и переработки коксующегося и энергетического угля на базе месторождения Добруджа (Болгария), горно-обогатительного комбината на базе месторождения коксующихся углей Таван-Толгой (Монголия), расширение угольных месторождений ПНР. Предполагалась также разработка и заключение Генерального соглашения о сооружении в СССР силами и средствами заинтересованных странчленов СЭВ Криворожского горно-обогатительного комбината, Михайловского горнообогатительного комбината (III очередь), Яковлевского рудника. Отдельно упоминалось строительство новых мощностей по добыче и производству никелесодержащей продукции на Кубе. Первое Генеральное соглашение в этой области было заключено еще в июне 1975 г.

Хотя в ДЦПС не конкретизировались мероприятия в нефтегазовом секторе, судя по условиям заключенных контрактов, именно нефтегазовый сектор Советского Союза становился главным объектом иностранных инвестиция. Вслед за разработкой Оренбургского газоконденсатного месторождения и пуском продуктопровода «Оренбург - Западная граница СССР», были заключены соглашения по строительству газопровода «Уренгой-Ужгород», также обеспечивавшего потребности экспортной торговли [13, С. 63].

Советские экономисты и функционеры в официальных публикациях позитивно оценивали влияние Комплексной программы, СПМИМов и ДЦПС, указывая, например, что они с началом их применения «укрепились плановые основы совместного строительства, расширились масштабы сотрудничества на многосторонней основе, возросло число отраслей производств, в которых строительство объектов осуществляется совместными усилиями, и др.» [1, С. 27].

Но принятие нормативных документов в 1970е гг. не играло значительной роли в активизации сотрудничества. Во-первых, крупнейшие проекты в сфере производства ископаемых ресурсов были разработаны и запущены до принятия СПМИМа и ДЦПС. Во-вторых, хотя Комплексная программа предшествовала второй волне взаимных инвестиций в сырьевом секторе, после ее принятия не произошло возрождения этой формы сотрудничества на территории Восточной Европы. Наоборот, имевшая место переориентация на разработку месторождений в глубине СССР в первой половине 1970x гг., отражала изменившиеся экономические условия, обусловленные началом роста цен на энергоносители в 1968-1969 гг.

Социалистические системы принципиально не могли решить проблему развития иностранных инвестиций, поскольку описанные ранее ограничения были заложены в самой природе инвестиционного процесса плановых экономик.

В 1980 году функционеры СЭВ и плановых, финансовых и внешнеторговых органов социалистических стран при обсуждении «Предложений по решению экономических и организационных условий сотрудничества при строительстве объектов совместными усилиями...» были вынуждены решать задачи сходные с теми, что решали их предшественники в 1963 - 1967 гг. По их мнению, требовалось направить усилия стран на дальнейшее совершенствование экономических и организационных условий сотрудничества при совместном строительстве объектов для определения стоимость 
строительства и долевого участия стран; наполнения долевого участия; уровня процента на кредиты в конвертируемой валюте; цен на продукцию, поставляемую с совместно построенных предприятий [8, Д. 288. Л. 20 - 45]. Попытка стандартизировать условия в очередной раз привела к спорам, хотя опыт сотрудничества в данной сфере накапливался более 20 лет.

Как и в середине 1960х гг. главным оказался вопрос издержек в твердой валюте. Конвертируемая валюта по-прежнему оставалась самым дорогим и дефицитным ресурсом. В документе прямо указывалось, на необходимость «создавать в начальной стадии переговоров [по совместным проектам] группы компетентных представителей для изучения и внесения предложений об освоении в странах-членах СЭВ соответствующей продукции с целью сокращения до минимума, а при возможности исключения затрат в конвертируемой валюте» [8, Д. 288. Л.30]. И также как в 1964 г. польская сторона пыталась переложить валютные издержки на страны-инвесторы, в 1980 г. это делали уже СССР и Куба. Разница заключалась в том, что новые чемпионы «инвестиционной привлекательности» настаивали на получении самой валюты, а не просто закупленного на нее оборудования [8, Д. 288. Л.31-32]. В свою очередь страны-инвесторы, в число которых входили Венгрия, ГДР, Польша, Румыния и Чехословакия, настаивали на том, чтобы МИБ выдавал валютные кредиты им, а не Советскому Союзу и Кубе ${ }^{5}$. Более того, делегации Венгрии, Польши и Румынии отстаивали свое право на реэкспорт продукции совместных предприятий, поставляемой в счет выплат по кредитам.

Ключевое условие для успеха реализации проектов долевого участия в сырьевой сфере не изменилось: страны-инвесторы, и страны-реципиенты в результате должны были сохранять или получать твердую валюту. Это было характерно и для проектов нефтегазового сектора, и для добычи других ископаемых. Так участие польских рабочих в строительстве горно-обогатительных комбинатов на территории СССР было призвано обеспечить сырьем металлургический гигант «Гута Катовице», продукция которого изначально предназначалась для валютного экспорта.

Попытки институализации совместного строительства на основе долевого участия в 1970-е гг. завершились принятием целого ряда документов. Однако нет оснований полагать, что эти документы играли значительную роль в расширении взаимных инвестиций: наиболее острые проблемы оставались нерешенными и в 1980е гг., а условия долевого участия по каждому проекту согласовывались отдельно.

\section{Выводы}

Совместные проекты в сфере добычи ископаемых ресурсов, построенные при долевом участии заинтересованных стран, были весьма специфической формой сотрудничества социалистических стран. Их распространение было важным признаком расширения экономического сотрудничества социалистических стран, но угрожало ростом напряженности внутри стран. В условиях жесткого дефицита ресурсов и напряженных планов развития народного хозяйства взаимные инвестиции могли осуществляться только в строго определенных условиях.

Как было показано, принципиальным условием для запуска проекта была потенциальная возможность снизить инвестиционную напряженность за счет увеличения объема свободной валюты для обеих сторон процесса - и для инвестора, и для реципиента. Стороны стремились сократить валютные издержки для реализации данных проектов до минимума. Вероятно, именно фактор валюты был самым строгим ограничением для международного сотрудничества. Существовали планы совместных производств со странами Северной Европы, но они не были реализованы именно из-за высоких валютных издержек.

Корнаи показал, что в плановых экономиках внутренние инвестиции осуществлялись в рамках инвестиционных циклов. По его мнению, внешнеторговая деятельность была одним из факторов, влиявших на фазы цикла. Существование проектов долевого участия в сырьевой сфере было частью этого процесса. Поскольку совместные производства создавались, как правило, в тех отраслях, где страны вынуждены были импортировать большие объемы сырья за твердую валюту, или имели возможность экспортировать излишки в капиталистические страны.

\footnotetext{
${ }^{5}$ Многосторонние расчеты и кредиты в МИБ рассчитывались по курсу переводного рубля к доллару, установленному МБЭС (на 1984 г. составлял 1:0,767), тогда как двусторонняя торговля с СССР по курсу рубля к доллару, установленному в Госбанком СССР $(1: 0,796)$. При этом переводной рубль к рублю неизменно оставался в отношении 1:1. Простая разница курсов давала 3,7 \%. О разнице курсов см.: Любский М.С.. Особенности международного социалистического инвестиционного кредита// Внешняя торговля СССР со странами СЭВ. М.: Наука, 1986. С.92.
} 
Попытки стандартизировать данный тип экономического сотрудничества предпринимались в рамках СЭВ с середины 1960х гг. и вплоть до середины 1980х гг. Появление нормативной основы для проектов долевого участия свидетельствовало бы о реальном углублении социалистической интеграции. Однако, даже появление подобных документов во второй половине 1970х гг. не сняло многих противоречий. Каждый новый проект был уникальным как по обстоятельствам появления, так и по конкретным условиям участия. С этой точки зрения, документы СЭВ носили описательный характер и мало влияли на реальное расширение сотрудничества.

\section{Дискуссионные вопросы}

Сотрудничество СССР и восточноевропейских стран было сложным многосторонним процессом, на который влияли как внутренние особенности функционирования конкретных плановых систем, так и мировая экономическая конъюнктура. Историки Холодной войны часто ограничиваются анализом двусторонних или трехсторонних экономических отношений, оставляя за рамками исследования наднациональный контекст этих процессов. Стоит отметить, что эта проблема характерна и для исследований Европейского Экономического Сообщества. Для ранних периодов интеграционных объединений, а в случае СЭВ - для любого периода его истории, разграничить двустороннее взаимодействие национальных государств и деятельность многосторонних или наднациональных структур чрезвычайно сложно. Это значительно затрудняет процесс изучения экономической кооперации социалистических стран.

Предложенный в данной статье вариант анализа бюрократических процедур Совета Экономической Взаимопомощи как организации в контексте конкретных событий двусторонних отношений, позволяет рассмотреть обе группы процессов в общем контексте, но у такого подхода есть очевидные недостатки.

В СЭВ ведущую роль играли двусторонние отношения, поэтому, весьма вероятно, что многосторонние обсуждения и консультация в структурах СЭВ в большинстве случаев не оказывали серьезного влияния на процесс принятия политических решений. С этой точки зрения, попытки институализации тех или иных форм сотрудничества отражают лишь уже достигнутые договоренности и пропитанные идеологией конвенциональные представления о перспективах развития. При этом, в дискуссия внутри профильных комиссий при СЭВ сложно разделить официальные позиции национальных правительств и конкретных бюрократических групп (отраслевых лобби, групп интересов и т.д.), поэтому затруднительно даже говорить о том, чьи представления отражены в этих дискуссиях.

Тем не менее, по крайней мере для отдельных направлений и форм сотрудничества документы СЭВ являются отличным источником, который позволяет взглянуть на сложный набор двусторонних договоренностей в широком контексте и в собственной логике плановых систем.

\section{СПИСОК ЛИТЕРАТУРЫ}

1. Батизи Е.Е. Инвестиционная политика стран СЭВ. М.: Наука, 1983.

2. Караваев В.П. Интеграция и инвестиции: проблемы сотрудничества стран СЭВ. М.: Наука, 1978.206 с.

3. Корнаи Я. Дефицит. М.: Наука, 1990. 608 с.

4. Липкин М.А. Советский Союз и интеграционные процессы в Европе: середина 1940-х - конец 1960-х годов. М.: Русский фонд содействия образованию и науке, 2016. 560 с.

5. Липкин М.А. «Мировой кооператив народов»: Совет Экономической Взаимопомощи, который пытался построить Н.С. Хрущев// Новый исторический вестник. № 4 (54), 2017. С. 121-144.

6. Пивоваров Н.Ю. Советские экспортно-импортные планы и их реализация: что продавал и что покупал СССР во второй половине 1950-х годов // Электронный научно-образовательный журнал «История». 2018. Т. 9. Выпуск 7 (71) [Электронный ресурс]. Доступ для зарегистрированных пользователей. URL: http://history.jes.su/s207987840002410-0-2

7. Российский государственный архив экономки (РГАЭ). Ф. 561. Оп. 14c.

8. РГАЭ. Ф. 561. ОП. 15.

9. РГАЭ Ф. 561. ОП. 28.

10. РГАЭ. Ф. 562. ОП. 28.

11. РГАЭ Ф. 4327. ОП. 77.

12. Шастико В.М. Внешняя торговля СССР со странами СЭВ. М.: Наука, 1986. 110с.

13. Широков О.Н. СЭВ в мировой экономике: современная оценка проблемы функционирования и значения. Вопросы истории, методологии и историографии. М: ИНИОН РАН РФ, 2005. 155 с. 
14. Durka B. Sąsiedzka współpraca PRL - CSRS, Warszawa: Krajowa Agencja Wydawnicza, 1986. 140 s.

15. Kansikas S. Socialist Countries Face the European Community. Soviet-bloc Controversies over East-West Trade, Peter Lang GmbH, 2014. 224 p.

16. Kornai J. Resource Constrained versus Demand Constrained Systems. Econometrica, Jul. 1979, Vol. 47, No. 4, pp. 801-819.

17. Popov A.A. Trade Expansion within the Council for Mutual Economic Assistance after the Polish and Hungarian Crises// Vestnik of Saint Petersburg University. History, 2018, vol. 63, Iss. 4, pp. 1303-1316.

18. Radisch E. The Struggle of the Soviet Conception of Comecon, 1953-1975// Comecon revised. Integration in the Eastern Bloc and Entanglements with the Global Economy. Leipzig: Leipziger Universitatsverlag, 2017. pp. 26-47.

19. Różański H. Spojrzenie na RWPG. Wspomnienia dokumenty refleksje. 1949-1988, Warszawa: Państwowe Wydawnistwo Naukowe, 1990. $306 \mathrm{~s}$.

20. Sanchez-Sibony O. Red globalization. The political economy of the Soviet Cold War from Stalin to Krushchev. Cambridge: Cambridge Univ. Press, 2014. 294 p.

21. Skrzypek A. Mechanizmy autonomii: Stosunki posko-radieckie 1956-1965. Pułtusk-Warszawa: Wyższ Szkoła Humanistyczna in. A. Gieysztora, 2005. 346 s.

22. Stone R. Satellites and Commissars: Strategy and Conflict in the Politics of Soviet-Bloc Trade. Princeton: Princeton Univ. Press, 1996, 283 p.

23. Biuletyn Informacyjny. Komitet Współpracy Gospodarczej z Zagranicą. 1964. Nr. 30., AAN. KWGzZ. sygn. $22 / 4$. Zb. 7-4

Поступила в редакцию 15.09.2019

Попов Алексей Алексеевич, кандидат исторических наук, доцент кафедры истории России и зарубежных стран ФГБОУ ВО «Челябинский государственный университет» 454001, Россия, г. Челябинск, ул. Бр. Кашириных, 129 E-mail: hammstergoshop@mail.ru

\section{A.A. Popov ECONOMIC MOTIVES OF COOPERATION OF CMEA COUNTRIES IN RAW MATERIAL PRODUCTION $(1950 s-1980 s)$}

DOI: $10.35634 / 2587-9030-2020-4-2-196-204$

On the basis of archival materials of the Russian State Geological Property and Economics, the article analyzes the economic incentives for cooperation between the countries of the Council for Mutual Economic Assistance in the extraction of mineral resources. The course of the discussion on the possibility of standardizing the mutual investments of the socialist countries was reconstructed. Investment mechanisms are considered in the logic of the functioning of planned systems based on the Janos Kornai model. It was revealed that one of the key conditions for the successful implementation of projects was the possibility of increasing the inflow of hard currency for all parties involved. The individual nature of most of the implemented projects predetermined the failure of attempts to standardize this form of cooperation within the framework of the CMEA regulatory framework. Given the prevalence of bilateral relations over multilateral forms of cooperation of socialist countries, attempts to institutionalize individual forms within the CMEA framework only recorded the current situation.

Keywords: CMEA, socialist camp, Cold War, European integration.

Received 15.09.2019

Popov A.A., Candidate of History, Associate Professor at Department of Russian and General History

Chelyabinsk State University

Brat'ev Kashyrinykh st., 129, Chelyabinsk, Russia, 454001

E-mail: hammstergoshop@mail.ru 